\title{
Introduction: Place-Based Sustainability Research in the Provincial North
}

\author{
Rebecca Schiff, Charles Z. Levkoe \& Lindsay P. Galway \\ Lakehead University
}

As one of the most sparsely populated countries in the world, Canada depends on widely dispersed rural and northern settlements to support the use and development of the country's agricultural and natural resources that are at the heart of Canadian livelihoods and the economy (Hallstrom, Beckie, Hvenegaard, \& Mündel, 2016; Markey, Breen, Gibson, Mealy, \& Ryser, 2015; Hodge, Hall, \& Robinson, 2017). The sustainability of these regional communities depends on a complex network of organizations dedicated to promoting the high standard of living for which Canada is recognized around the world (Hodge et al., 2017; Hall, Vodden, \& Greenwood, 2016; Halseth \& Ryser, 2016; Schiff, 2014). For example, a 2013 inventory of regional development organizations in Newfoundland and Labrador identified more than 1,000 organizations involved in development at the regional scale in that province (Vodden, Hall, \& Freshwater, 2014). The future challenges of Canada's regional centres are among the country's key future challenges.

To consider these issues, we hosted the workshop "Regional centres and the sustainability of Canada's rural and northern landscapes” in May 2018 at Lakehead University (supported by funding from the Social Sciences and Humanities Research Council of Canada). Our aim was to explore the role of regional centres in Canada's development as a nation and the role that they will play into the future. The workshop brought together researchers 
from regional centres across the country to focus on key challenges across the landscape of Canada's Provincial Norths. Ken Coates, Canada Research Chair in Regional Innovation at the Johnson-Shoyama Graduate School of Public Policy at the University of Saskatchewan delivered a keynote presentation on regional policy in Canada. He discussed ways that regional centres can prepare for an uncertain future dominated by rapid technological change, mobile workforces, and the need for culturally appropriate social and health services.

Over two days the participants met to share perspectives and establish connections. More specifically, by reflecting on the special role of regional centres and their place in addressing Canada's future challenges, we hoped to lay the groundwork for research focused on supporting the emerging needs of regional centres, and the rural and remote communities that they support. By exchanging narratives, histories, and perspectives among cultures from across the country, we sought, from a national perspective, to anticipate the role that regional centres will play in Canada's future.

This special collection in the Northern Review is meant to provide a glimpse into some of the conversations and issues discussed over the course of the two-day workshop. While this collection could not include the full breadth of the issues faced in regional centres, it does provide a look at critical issues-developing and supporting resilient local and regional food systems (Connie Nelson and Mirella Stroink); supporting small-scale commercial fisheries that have played an important role in northern food security, food sovereignty, and regional economies (Kristen Lowitt, Charles Levkoe, and Connie Nelson); northern rural sustainability planning and policy (Rebecca Schiff); community-based participatory research approaches to addressing housing and homelessness issues (Marleny Bonnycastle and Maureen Simpkins); and new tools for postsecondary education, which can encourage a deepening of conversations about place-based sustainability (David Greenwood and Devon Lee). These articles provide insight into the many strengths of, and challenges facing, northern, regional centres, and highlight our collective work toward development of more sustainable northern communities and regions. 


\section{References}

Hall, H, Vodden K, \& Greenwood R. (2016). From dysfunctional to destitute: The governance of regional economic development in Newfoundland and Labrador. International Planning Studies, 22(2), 49-67. https://doi.org/10.10 80/13563475.2016.1167585

Hallstrom L, Beckie M, Hvenegaard G, \& Mündel K. (2016). Sustainability planning and collaboration in rural Canada: Taking the next steps. University of Alberta Press.

Halseth, G., \& L. Ryser. (2006). Trends in service delivery: Examples from rural and small town Canada, 1998-2005. Canadian Geographer, 43, 69-90. https:// journals.brandonu.ca/jrcd/article/view/40

Hodge G, Hall H, \& Robinson I. (2017). Planning Canadian regions ( $2^{\text {nd }}$ ed.). UBC Press.

Markey S, Breen S, Gibson R, Mealy R, \& Ryser L. (2015). The state of rural Canada 2015. Canadian Rural Revitalization Foundation/Fondation canadienne pour la revitalisation rurale.

Schiff, R. (2014). Rethinking governance: Supporting healthy development through systems-level collaboration in Canada's provincial north. The Northern Review, 38, 133-154. https://thenorthernreview.ca/index.php/nr/ article/view/329

Vodden K, Hall H, \& Freshwater D. (2014). Understanding regional governance in Nerwfoundland and Labrador: A survey of regional development organizations. Memorial University.

\section{Guest Editors}

Rebecca Schiff is associate professor in the Department of Health Sciences at Lakehead University in Thunder Bay, Ontario.

Charles Z. Levkoe is associate professor, director of the Sustainable Food Systems Lab, and Canada Research Chair in Sustainable Food Systems at Lakehead University in Thunder Bay, Ontario.

Lindsay P. Galway is associate professor in the Department of Health Sciences at Lakehead University in Thunder Bay, Ontario. 